\title{
Chapter 20 \\ Mediation and Conciliation in Collective Labor Conflicts in the USA
}

\author{
Arnold M. Zack and Thomas A. Kochan
}

\subsection{Introduction}

Mediation is widely used to help resolve collective disputes in the United States. ${ }^{1}$ In many instances it is required by statute, but it is relied upon even when not mandated. Mediation takes on a crucial role in the absence of any governmental facility imposing wages, hours or working conditions on unionized employees. When comparing the place of mediation in United States with its use in other nations one must recognize that federal legislation applies to those in federal employment as well as those employed by private sector enterprises engaged in interstate commerce, while each of the fifty states have jurisdiction over those in state and municipal employment within their jurisdictions and those in enterprises NOT engaged in interstate commerce. That understanding is important when evaluating the overall role of mediation in collective dispute resolution in the United States where in 2017, 6.4\% of the private sector and $34.4 \%$ of the public sector was unionized. ${ }^{2}$ Thus, collective dispute resolution in the private sector is largely guided by the laws and role of the federal government, while within states such issues are handled by the widely varying laws and roles of the respective states, with differing authorization of collective bargaining, and the use of mediation.

\footnotetext{
${ }^{1}$ For more background on mediation see: John T. Dunlop and Arnold M. Zack, Mediation and Arbitration of Employment Disputes. Jossey-Bass Publishers, 1997, Zack (1985).

${ }^{2}$ The Bureau of Labor Statistics in January 2018 reported a new low in union membership for 2017 of 10.7\%. cpsinfo@bls.gov, www.bls.gov/cps. 1 Although about a quarter of federal government employees are unionized, wages and hours are largely determined by Congressional statute and are thus not subject to negotiation or mediation. www.bls.gov/news.release/union2.nr0.htm.
}

Support for preparation of this paper were provided by the Mary Rowe Fund for Conflict Management.

\section{A. M. Zack · T. A. Kochan $(\bowtie)$}

MIT Sloan School, 100 Main St., Cambridge, MA 02139, UK

e-mail: tkochan@mit.edu 
Mediation is a voluntary tool often used for resolving disputes even if not statutorily mandated as a required step toward settlement (Dunlop and Zack, 1997). In addition, if mediation initially fails, it is often returned to again later in negotiations, formally or informally perhaps even to help end a strike. In the United States the federal and state governments employ full time career mediators on a salaried basis. Private mediators selected by the parties charge for their services on an hourly or daily basis and usually combine that role with work as labor management arbitrators, academics or on occasion as lawyers or members of the clergy.

\subsection{Characteristics of the System}

\subsubsection{Statutory Authority}

In the interstate private sector, the parties are required by the National Labor Management Relations Act (LMRA) of 1947 to notify the Federal Mediation and Conciliation Service (FMCS) an independent Federal agency, when they commence bargaining over new or renewed collective bargaining agreements.

Although disputing parties have the option of finding and employing their own private mediators, most interest mediation in the US is provided by the FMCS which has a roster of approximately 240 mediators stationed in 10 District Offices and more than 60 Field Offices throughout the United States. In 2016 the FMCS monitored approximately 11,734 negotiations and actually mediated 3540 cases of collective bargaining contract negotiations $(10,678$ in the private sector, 1056 in the public sector), with a settlement rate of $85.5 \%$ (up from $84 \%$ in 2012 and 2013). State provided and party initiated mediation is not as pervasive, but presumably has the same settlement rate. Privately initiated mediation may have an even higher rate of settlement inasmuch as the disputants pay for their mediator, and may have a higher expectation of settlement. In addition to its primary function of mediating labor management collective bargaining disputes, the FMCS also provides mediators for rights or grievance disputes. In 2016, it mediated 1670 grievance mediation cases securing agreement in 1264 cases, a $76 \%$ success rate.

Aside from mediation, the FMCS maintains a roster of 5400 private rights arbitrators and pursuant to 12,000 joint requests from management and unions in 2016 appointed single arbitrators in 5400 grievance arbitrations.

The FMCS also ran 1941 training programs for labor and management teams in firms on negotiations and problem solving methods in 2016.

\subsubsection{The Process}

The FMCS assigns a mediator from its roster of full time mediators, to monitor contract negotiations and, if requested by both parties, to provide mediation services to 
help narrow the differences between them on procedural as well as substantive issues. These mediators continue to be available to the parties throughout their relationship, and may, if requested, also mediate individual rights disputes often as a component of the negotiation of the parties' collective bargaining contract. As mentioned, in 2016 the FMCS mediated 3540 disputes. ${ }^{3}$ The FMCS may also be asked to provide training, to facilitate labor management committees dealing with particular workplace issues and to mediate individual employee grievances. In recent years, the FMCS has also undertaken assistance to parties in using "interest based" negotiations techniques that will be discussed below. Most states have comparable agencies to serve enterprises that do not meet the federal standard of interstate commerce and to help resolve disputes with unions of state and local government employees. For those states without such facilities, arrangements are often made for FMCS mediators to provide help to disputants.

Another statute, The Railway Labor Act (RLA) was enacted in 1926 to provide dispute resolution services for railways and the thirteen unions representing their employees. Through subsequent amendments that jurisdiction now serves parties in the airline industry. The 1934 amendments to the RLA created a government agency, the National Mediation Board (NMB), which provides mediation services for the transportation industry equivalent to those provided to the rest of the private sector by the FMCS. In addition, when the President of the United States declares that a potential strike of railway or airline employees threatens the national health and/or safety, he appoints a Presidential Emergency Board of 3-7 neutrals who enter the dispute after strenuous and often prolonged staff mediation, triggering a mandatory 30 day "cooling off period" during which it conducts hearings and may further mediate before issuing recommendations to the parties for the resolution of their impasse. There have been approximately 220 such Emergency Boards created since 1934. The Boards meet with the parties and write a report with recommendations for settlement that then may be submitted to the U.S. Congress. Normally, the parties resolve their dispute by using the recommendations as a basis for further negotiations, sometimes with further mediation assistance with either a federal mediator or one of the neutrals who served on the Emergency Board.

To handle disputes involving the federal government and its own employees, The Civil Service Reform Act was passed in 1978, establishing the Federal Labor Relations Authority (FLRA) to provide two million federal employees with rights comparable to those provided to the private sector in 1935 by the National Labor Relations Act. The Authority provides assistance to federal agencies in developing dispute resolution services including mediation, and through the office of the Federal Service Impasse Panel may seek the assistance of FMCS mediators to help resolve collective bargaining disputes between federal agencies and the unions of their employees.

\footnotetext{
${ }^{3}$ https://www.fmcs.gov/wp-content/uploads/2017/01/AnnualReport2017Jan13.pdf; 2435 of those cases were in the private sector, 508 involved state and municipal governments, 318 were in the federal sector.
} 


\subsubsection{Non-statutory Use of Mediation}

Mediation is widely recognized as the most effective device for achieving resolution of collective disputes when the parties fail to achieve agreement in their direct negotiations. Thus, in states where there may be no dispute resolution agency, or where the state's provision of a mediator might be unacceptable, it is not uncommon for the disputants to invoke mediation by non-government, not full time, neutrals. At the outset of public sector collective bargaining in the 1960s, many unions in the public sector, wary of using mediators on the payrolls of their government employers, turned to private arbitrators or others with labor management experience to mediate their contract negotiations. In addition to such ad hoc mediation roles, these private sector neutrals were routinely enlisted to serve as fact finders, in the next statutory step following unsuccessful mediation. Their fact finding reports were envisioned as texts that both summarized the issues and provided recommendations that would hopefully help the parties move toward resolution of their disputes. Although on its face fact finding suggests a formal hearing and issuance of recommendations for settlement based thereon, the expectation that such recommendations would result in their acceptance by the disputants necessitates the crafting of recommendations having the highest prospect of acceptance. This dynamic in turn, focuses the role of the fact finder on determining which elements of a package most likely acceptable to end the dispute. The fact finder usually resorts to mediation as the most effective means of eliciting such information from the parties that would best enable the crafting of acceptable recommendations, all without wearing the formal title of mediator.

\subsection{Characteristics of the Mediators and Traditional Mediation}

Although the term mediator would suggest a neutral who meets with disputants to bring them to an agreed upon resolution of their conflict, such a dictionary use of the term minimizes the unique demands placed on such an individual to be effective in communicating and persuading opponents that compromise of often fiercely held positions should be reevaluated focusing on settlement as their preferred course of action. The labor-management mediator not only seeks to reduce the difference between the parties by nudging them closer together, an effort that on its face might require little substantive expertise. The mediator more importantly routinely offers suggestions for recasting the issues, offering new or revised approaches to lessening the differences. That requires a level of substantive expertise that usually requires years of experience dealing with those same issues. To best capture that experience the state and federal agencies have largely drawn their mediators from the ranks of advocates with years or even decades of negotiating experience. While those recruited into the ranks of full time mediators have usually had experience on only one side representing solely unions or management, their continued relationship with their 
counterparts on the other side has given them experience on the issues shared with their adversaries. In addition to those with extensive experience as advocates, the agencies are increasingly hiring younger candidates with academic backgrounds, pairing them with the former advocates to bring newer cadres up to an experience level where they can mediate such disputes on their own. This approach has been helpful in building a contemporary roster of professional mediators that is becoming more diverse as to gender, race, and age.

As noted above, in addition to full time government employed mediators, such work is also performed in ad hoc fashion for disputants or government agencies which call upon labor management neutrals to mediate their disputes. The frequency of their use is restricted by the fact that unlike government employed mediators whose services are provided free of charge to the parties private mediators routinely charge the parties or a designating government agency for their time.

The most successful labor management mediators also need abundant "people skills". Mediators are often characterized as being patient, sensitive, tolerant, innovative, analytical, impartial and even humble with a good sense of humor. Such attributes are not universally found in all mediators, but it is clear that those who are most effective, considering they may be dispatched by either side if deemed persona non-grata, are those whom the opposing parties consider informed and personable, nonpartisan and innovative as they seek to push the parties ever closer together. ${ }^{4}$ There is no formal training, certification or registration of mediators; anyone jointly acceptable to disputants to bring them to settlement can embrace that title. The efforts of all engaged in the mediation are universally considered private and confidential.

\subsection{Description of the Process}

There is no prescribed formula for mediators to follow in doing their work. Each case is usually handled by a single mediator, unless training another. If unacceptable he or she may be replaced. Given the requirement of continual tolerance by the disputing parties, the mediator must build up confidence in his or her skill and impartiality while developing knowledge of the parties' dispute and providing prescriptions for joint resolution. We describe below, first, the process as it has traditionally functioned. Thereafter we describe "interest based bargaining" (IBB), a newer and increasingly popular innovation.

\footnotetext{
${ }^{4}$ For a study of the determinants of mediation effectiveness, including measures of mediator characteristics, see Kochan and Jick (1978).
} 


\subsubsection{Mediation of Traditional Positional Negotiations}

\subsubsection{Initial Joint Session}

In typical negotiations the mediator enters the negotiations after the parties have already formulated their lists of demands or issues to be considered and have presumably deadlocked in direct negotiations (Walton and McKersie, 1965). Moreover, even if the parties may know their mediator, it is quite likely that at least some of the negotiating team members are new to the process and to the mediator. Thus, the mediator must initially explain the process, the mediator's role and expectation of the parties, providing assurance that each team will retain the right to determine the final terms of any agreement. Such opening sessions also provide an opportunity for the mediator to get to know the teams and particularly their spokespersons. (Union negotiating teams normally consist a small number of union members who serve on a negotiating committee along with a lawyer or union officer who serves as the spokesperson; employers are normally represented by a lawyer or staff labor relations professional and several other managers from the organization). This is the point at which the mediator would set forth expectations for the process, that the proceedings be private between the two teams with the press excluded, that each team have a single spokesperson (who could delegate to other team members as desired) and that the participants pledge to refrain from talking to outsiders about what is transpiring (with the mediator sometimes reserving the right to make occasional statements to the press).

To avoid any charges of favoritism by initially talking to the "other" side, mediators usually commence their role in a joint session to meet the teams, to diffuse any suspicions of bias and to begin building trust of both sides. If the mediator feels sufficiently comfortable in her or his initial role, he or she may ask each side to identify the issues in dispute. Often such presentation with opponents in the same room may become volatile, a timely excuse for the mediator to separate the parties and begin meeting with one side at a time. If the initial joint session is not stormy, it informs as to what is in conflict, and indeed, with sufficient back and forth will help the mediator gain a sense of the parties' priorities among the issues, and within the teams. Sometimes, if lucky, that session might even last long enough to enable the disputants, feeling sufficiently comfortable, to provide some indication of how they might adjust their positions to narrow the dispute. At the end of such joint session, whether volatile or peaceful, the mediator will usually meet with each team for a more candid assessment of positions. Even the selection of which team to meet separately with first may trigger protest from the parties, so the mediator may explain his or her choice is dictated by choosing the moving party, the party seeking change in the status quo or the party with the more suitable venue for meeting, or by just saying that the initial party meeting will be with the team using the room in which they are then meeting. 


\subsubsection{Caucus with One Team}

In meeting each side, the mediator has the opportunity of inquiring as to the perceived priorities of proposals on both sides, and with critical questions probe the seriousness of the proposals of the two teams. The goal of the mediator is always trying to cast doubts as to the convictions of the proponents of a proposal, to point out the risks of a team continuing to adhere to a position, and to propose innovative alternatives to encourage the team to move to alternative positions that might be more acceptable to the other side. Such single team meetings enable the mediator to assess the team dynamic and assess whether the official spokesperson is indeed the person with the power to alter positions. Often the spokesperson is NOT that person, with someone else vetoing proposals that come up in the session or proposing new positions, even instructing the spokesperson as to how to represent the team. The mediator has to be careful to respect both but identifying the real possessor of power enables the mediator to accommodate to the real leaders' initiatives. Not to be confused with the power center is the spoiler or naysayer, who may be even more outspoken, but whom the mediator must evaluate in terms of the receptivity of the rest of the team to his or her interventions to avoid being misled as to the true thinking of the team. Such individual may be championing a specific issue and presence in the team caucus enables the mediator to assess whether the championed issue is just personal and suitable to being shelved or ignored, or something that rest of the crew seriously considers. Determining the answer to that question will enable the mediator to nudge the team's position along lines that give appropriate weight to that person's idea, constituency, respect and role in the team, and impact on any final team position.

After the initial joint meeting, and sessions with separate teams, the mediator will have a sense of how to proceed. If the separate team meetings have moved the process forward with recast positions, if there are procedural questions or factual questions from both sides, the mediator might reconvene a joint session to allow the spokespersons to make revised presentations or use the session to ask questions on issues if confused or uninformed. More likely, if the separate meetings raise questions for clarification, the mediator will more likely seek answers by moving directly to the other team for a quick answer.

The mediator may find it most convenient going back and forth between the teams, asking questions, carrying proposals, and proposing adjustments of positions. Such shuttle mediation may be more efficient, but the mediator has to be careful not to spend too much time with either team for fear of conveying the impression that he is more comfortable with one team than the other. Coming into the room of the seemingly neglected team, the mediator might make some comment about how difficult that last meeting with the other team had been, how long it had taken, or how difficult it had been to get them to move.

\section{Caucus with spokespersons}

After the teams have had some exposure to the mediator and hopefully begun to have a sense of confidence in the mediator's role in the developing process, the mediator might pull the spokespersons away from their teams to enlist them in his 
strategy for bringing the parties together. Asking their advice on how to proceed or eliciting their view on their positions, tends to enhance the spokes persons sense that the mediator values their role. Mediators always face the dilemma as to whether to deal first with the big "strike" issues like wages or the small issues such as parking space allocation, personal leave, etc. If the big issue such as wages is first resolved it usually brings a sense of relief, and satisfaction, hopefully making it easier to dispose of the other "non-strike" issues. Other mediators feel that reaching agreement on the small "non-strike" issues develops a sense of accomplishment and initiates a sense of momentum that may lead to fruitful consideration of major issues. The caucuses with spokespersons is a valuable tool for the mediator, not only in developing the agenda, but perhaps more importantly as a tool for assessment of progress, for floating new ideas, or for privately resolving the inevitable tensions that arise when a team member says something inappropriate or leaks a position, or when the mediator has erred in transmitting a message. Such conferences are often the most efficient and most productive way to proceed. To be fruitful such sessions require that the spokespersons have the confidence of their teams that their independence is trusted, respected and credible, that the teams recognize that their agenda is in safe hands and that their spokesperson may make proposals and counter offers that while departing from that agenda would be helpful in narrowing differences. For example when confronting the inevitable "boulder in the road" an insistence by one side that it will not discuss any other items until their boulder issue is resolved, it is often crucial to the mediator to be able to assess the priorities of the team leaders, and to hear their candid prescription for being able to move forward. Assuming both spokespersons share the goal of settlement, such candid hallway discussions may be the key to restoring movement in the process.

Such hallway sessions provide a safe format for putting forth "supposals", not formal proposals but feelers to gauge what would be the response if a formal proposal were made on a topic at issue. In some very secure relationships where the mediator has long experience with the spokespersons, it is not unknown for them to meet with the mediator even before the commencement of the formal mediation to jointly develop a scenario which all three will follow in the mediation itself, not only for some mutually identified issues the spokesmen anticipate are readily solvable, but to lay out the parameters of the bigger issues creating an atmosphere making them more likely of expedited resolution. After such a caucus, it is usual for the spokespersons to return to their teams to report on what transpired in the caucus and then, apart from the mediator adjust their formal positions for transmission to the mediator, or across the table in a joint session.

Sometimes when an issue is very complicated, or if there is need for specialized information, the mediator may create a joint committee with team members experienced in that subject, to try to achieve agreement on data, on figures such as the components of budget item, or the projected cost of the proposals from both sides, or the consequences of a change in contract language impacting on disputed numbers of employees, on timing, etc. Through the combined format the mediation continues, perhaps over many days until the issues are resolved by agreement on the disposition of all initial issues, or until there is joint recognition that settlement is beyond reach. 
One of the uncomfortable tasks of the mediator is to assure the teams stay at the bargaining table, and do not invoke premature termination of the mediation. Often sessions run late into the night, taxing all involved. It is usually up to the mediator to cajole the teams to keep at it, promising perhaps early resolution, but always stressing that this is their best chance of getting resolution, and that a premature break in the proceedings at this time, will only encourage back sliding, and external pressure, making it impossible to get back in the future to the better spot in which they currently find themselves, uncomfortable and tiring though it may be.

\subsubsection{Reconvening Joint Sessions}

The mediator must be sensitive to the perceptions of both teams at all times, to make sure they feel involved in the process, and that they have had the opportunity to contribute their ideas. This is particularly true if the mediator spends what the team participants claim is too much time meeting privately with the spokespersons, or even while meeting with the other team. A report back from the spokesperson to his or her team that all is going well, may not overcome their feelings of neglect. Accordingly, the perceptive mediator will try to head off such concerns by calling occasional joint sessions if only to assure the members of both teams that they are involved. Reconvening to report on the status of the negotiations, or perhaps even to apologize for a mediator's misstep in misreporting a message, helps to improve that sense of participation. Many mediators, focusing on the issues from an outsider's perspective tend to forget that the members of the two teams, while adversaries in this drama, are really daily workmates, probably uncomfortable at being thrust into their adversarial role. Bringing the two teams together provides them the opportunity to reconnect with their workmates even though in opposing teams. Arranging for joint sessions for coffee breaks or catered/takeout meals tends to reduce inter-team tensions, reinforce or preserve personal relationships and encourage the view that the dispute is a shared problem that all need to help resolve. Additionally, a joint session is often called by the mediator when there is a breakdown or failure of movement, when the mediator needs to impress upon the members of both teams the imperative of adjusting positions for the process to move forward. While mediators often invoke the "chamber of horrors" prospect to each side to induce them to revise their deadlocked positions, that technique is also helpful when addressed to the convened both sides to alarm them to the prospects of failure of the mediation, the adverse results that both teams might confront if their dispute is not resolved. Hopefully that dismal forecast will be enough to redirect the team efforts, or at least encourage one or more members of the two teams to advise their spokesperson of the imperative to adjust their demands in order to get the mediation back on track.

The mediation continues with individual team and joint sessions, as well as caucuses until the "final" session. That meeting will announce the success or failure of the mediation. 
If successful, the parties will convene with the list of issues they had raised discussed, resolved and then jointly noted as "tentatively agreed to" (TAs). It is then left to a scrivener, from either party or perhaps the mediator, to write up a final document reflecting all those TAs for signature. The document may be written out in full, but more likely, since most settlements are revisions to terms in the parties existing collective bargaining agreement, it will be left to the principals themselves to prepare the final agreement integrating the agreed upon alterations. Usually, for an agreement to become legally binding requires ratification by the union membership, and perhaps if it a public sector employer, by a state or local legislature. In such cases, the parties, usually pleased with or relieved by, having reached their agreement, recognize that they may be forced back to the negotiating table, and perhaps even to a continuation of the mediation, if their agreement is rejected in that process.

If the final meeting is to announce the collapse of mediation, the mood will presumably be dour, since the dispute remains unresolved and a strike or lockout may be in the offing. But that breakdown is inevitably temporary since the parties at some point have to resume negotiations. Whether that breakdown is short or long term, the mediator will usually refrain from declaring the negotiations are finished to avoid the problem of trying to reinitiate them when one or both parties feel compelled to return to the bargaining table. Additionally, it is not unusual for one of the parties to suddenly come up with a new idea after the negotiators have decamped. Accordingly, mediators will usually declare that the mediation is adjourned until one of the participants asks the mediator to reconvene the teams; even the mediator might come up with a new, perhaps even a settlement-clinching idea during the trip home, leaving a door open to reconvening the parties.

\subsubsection{Interest-Based Mediation and Facilitation}

In recent decades there has been growing endorsement of a variation of the above process in what has become known as "interest-based bargaining." (IBB). It is increasingly embraced by the younger and more diversified negotiators and neutrals because it emphasizes innovative problem solving techniques seeking agreements that reflect and emphasize the shared interests of the parties. Some have referred to this as "integrative or mutual gains bargaining". 5

Typically, IBB processes begin well before negotiations, with the mediator(s) (often called facilitators) training the union and management teams in problem solving techniques. ${ }^{6}$ This typically involves training in ways to encourage information sharing, conducting joint research on possible root causes of issues or pending problems that are of concern to one or both parties, brainstorming of ideas in open dis-

\footnotetext{
${ }^{5}$ Richard E. Walton and Robert B. McKersie, A Behavioral Theory of Labor Negotiations. New York: McGraw Hill, 1965.

${ }^{6}$ For a detailed case study of a large IBB training and facilitation process see McKersie et al. (2008).
} 
cussions among all participants, generating multiple options for addressing issues, creating committees to generate and analyze options, and discussing ground rules for the actual bargaining process.

The actual bargaining process typically involves two groups, sometimes with overlapping membership. One group serves as the "main table" negotiators, i.e., the highest level representatives on the union and management teams who are responsible for reaching tentative agreements subject to final approval by the top management or ratification by the union membership. The second group involves worker and employer leaders with knowledge and experience in dealing with specific issues or that reflect different demographic or other interested participants in the employment relationship. They may be called on to participate in subject-specific subcommittees.

In the initial stages of an IBB-facilitated negotiations the participants review the ground rules for conducting the negotiations committing everyone to following the problem-solving protocols discussed in the pre-negotiations training. The parties then identify their basic interests in the negotiations. The goal at this stage is to avoid the more traditional "positional" approach to bargaining when the spokespersons state (or perhaps overstate) their list of "demands". Early in the IBB process the parties may agree to create one or more subcommittee to explore options on specific issues reflecting their top priorities. The mediators/facilitators often help these subcommittees invoking the problem-solving training that preceded negotiations. They often remind subcommittee members that they needn't reach final agreement on the issues assigned them. Instead, they should try to agree on one or more options to bring back to the main bargaining table for further or final consideration. On occasion of course, they might agree on a best way of resolving "their" issue. Success at this level requires full confidence in the data provided by the participants; if one or both parties is found to have been less than honest to score a later "win" it will obviously reduce trust and effectiveness of utilizing IBB in future negotiations.

Once the various subcommittees report their recommendations, the mediator/facilitator helps the representatives at the main table consider reported issues as well as other issues that had earlier been reserved for the representatives at the main table for their consideration. This is usually the most intense part of an IBB process involving some mixture of the more traditional mediation/negotiations processes described in the prior section and more creative exploration of ways to combine the various recommendations into a settlement package that best addresses the parties shared and often diverse interests carrying the spirt of cooperation into the day to day employment relationship. Unlike traditional mediation, this approach may involve multiple mediators/facilitators among the sub tables and even at the main table.

Interest-based mediation/facilitation has increasingly been used in both public and private sector settings. While no national data on the frequency of its use are available, in Massachusetts, for example, neutral facilitators have trained and facilitated negotiations for over forty school districts and teacher unions. Follow-up studies have shown IBB users to be more highly satisfied with their bargaining relationships 
and results than those that have continued to use more traditional approaches. ${ }^{7}$ Perhaps the best known use of IBB in the private sector has been by the large health organization Kaiser Permanente and the Coalition of Kaiser Permanente Unions. ${ }^{8}$

IBB is not a panacea for all labor relations problems nor is it likely to be effective in all settings or for all issues. It is, however, a promising option for dealing with the increasingly complex issues confronting labor and management, or when parties protest frustration over their traditional bargaining. But success with IBB requires consent and support of both parties to the negotiations as well as the executives and workers who must ratify (vote to accept) the agreement and live under its terms. It is most effective in settings where the parties already have cooperative relationships in their day-to-day labor management relationship, have received training in IBB, and/or are determined to significantly change from a more arms-length relationship going forward.

\subsection{Effectiveness of the System}

While few reliable statistics are available to track the effectiveness of mediation, FMCS and state government data indicate it has helped the parties reach agreements in most of the cases in which it is used. ${ }^{9}$ For 2016 the FMCS reported a settlement rate of $85.5 \% .{ }^{10}$ This likely understates the full contributions made by mediation since it misses those "preventive" mediations and/or trainings that help the parties prepare for and carry out successful direct negotiations on their own. Yet, the public has little appreciation of the role of mediation in preventing labor management strikes and their economic and societal impact. Indeed, the number of strikes during negotiation of new contracts involving 1000 or more workers has declined by more than the proportionate decline in union membership. In 2016 there were only 15 such strikes or lockouts involving more than 1000 workers, compared to 470 in $1952 .{ }^{11}$ Whether this is simply a reflection of declining union power to strike or increased effectiveness of negotiation and mediation cannot be determined. Clearly, however, both are part of the reason for the decline in strike activity in the U.S. It should be noted that strikes during the life of a collective bargaining agreement in the United States are very rare. Provision of final and binding arbitration is universally negotiated into collective bargaining agreements in exchange for the unions' surrender of the right to strike over issues of discipline, as well as contract interpretation and application.

\footnotetext{
${ }^{7}$ Barry Bluestone, Thomas Kochan, and Nancy Peace, "Getting Along: A better approach to public sector collective bargaining can improve labor relations and schools." Commonwealth Magazine. Spring, 2016. https://commonwealthmagazine.org/education/getting-along/.

${ }^{8}$ Robert McKersie, et al, 2008.

${ }^{9}$ Joel Cutcher-Gershenfeld, Thomas Kochan, and John Calhoun Wells, "In Whose Interest? A First Look at National Survey Data on Interest-Based Bargaining in Labor Relations." Industrial Relations. Vol. 40, January 2001, 1-21.

${ }^{10} \mathrm{https}: / / w w w . f m c s . g o v / w p-c o n t e n t / u p l o a d s / 2017 / 01 / A n n u a l R e p o r t 2017 J a n 13 . p d f$.

${ }^{11}$ Bureau of Labor Statistics, https://www.bls.gov/news.release/wkstp.nr0.htm.
} 


\subsection{Conclusions}

The low rate of unionization in the United States limits the number of potential labor management conflicts and strikes in the country. Except in the rare circumstances where workers may engage in a protest on their own without formal union representation, it is only in the unionized sector where there is collective bargaining and the prospect of breakdowns which would trigger mediation or facilitation. The evidence of the continuing drop in workplace strikes suggests that the system of mediation has been effective over the decades and has proven to be a flexible process for adapting to the changing issues and needs of the parties and to new approaches to labor management relations.

It is difficult to make predictions about the future of mediation. On the one hand, if unions continue to decline in number and membership, so too will the use of mediation. On the other hand, pressures for increased wages and improved conditions and better funding of education and other public services appear to be producing increased militancy among teachers and other government workers. If this continues and spreads, strikes may begin to grow in number again and use of mediation may likewise increase. Thus, while the future is uncertain, the track record of successful use of mediation will stand the test of time and, if called on to do so, is a process that can once again help the parties shape effective union-management relations in the years ahead.

\section{References}

Dunlop, J. T., \& Zack, A. M. (1997). Mediation and arbitration of employment disputes. Jossey-Bass Publishers.

Kochan, T., \& Jick, T. (1978). The public sector mediation process: A theory and empirical examination. Journal of Conflict Resolution, 22, 209-240.

McKersie, R. B., Kochan, T., Sharpe, T., Eaton, A., Strauss, G., \& Morgenstern, M. (2008). Bargaining theory meets interest based negotiations: A case study. Industrial Relations, 48, 66-91.

Walton, R. E., \& McKersie, R. B. (1965). A behavioral theory of labor negotiations. New York: McGraw Hill.

Zack, A. M. (1985). Public Sector Mediation. Bureau of National Affairs. 
Open Access This chapter is licensed under the terms of the Creative Commons Attribution 4.0 International License (http://creativecommons.org/licenses/by/4.0/), which permits use, sharing, adaptation, distribution and reproduction in any medium or format, as long as you give appropriate credit to the original author(s) and the source, provide a link to the Creative Commons license and indicate if changes were made.

The images or other third party material in this chapter are included in the chapter's Creative Commons license, unless indicated otherwise in a credit line to the material. If material is not included in the chapter's Creative Commons license and your intended use is not permitted by statutory regulation or exceeds the permitted use, you will need to obtain permission directly from the copyright holder.

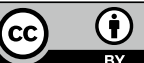

